\title{
Sensorimotor Gating Characteristics of Violent Men with Comorbid Psychosis and Dissocial Personality Disorder: Relationship with Antisocial Traits and Psychosocial Deprivation
}

Ottilie Sedgwick ${ }^{1,2 *}$, Susan Young ${ }^{2,3}$, Ben Greer ${ }^{2}$, Jack Arnold², Aisling Parsons², Ignazio Puzzo ${ }^{2}$, Mariafatima Terracciano ${ }^{1}$, Mrigendra Das ${ }^{2}$ and Veena Kumari ${ }^{1 *}$

1. Department of Psychology, Institute of Psychiatry, Psychology \& Neuroscience, King’s College London, UK

2. Forensic Research Domain, Broadmoor Hospital, West London Mental Health Trust, UK

3. Centre for Mental Health, Department of Medicine, Imperial College London, UK

*Correspondence to:

Veena Kumari, PhD, Research and Development, Sovereign Health Group, 1211 Puerta Del Sol, STE 270, San Clemente, CA 92673, USA; Email: v.kumari@sovhealth.com

Ottilie Sedgwick, PhD, Department of Psychology, Institute of Psychiatry, Psychology \& Neuroscience, King's College London, PO 78, De Crespigny Park, London SE5 8AF. Email: ottilie.sedgwick@kcl.ac.uk 


\section{Abstract}

Evidence suggests violence amongst those with psychosis is not aetiologically homogeneous, and that a large proportion of those who engage in violent behaviour have a comorbid antisocial personality disorder. Initial investigations indicate that this subgroup has distinct historical and neuropsychological characteristics, which may indicate diverse treatment needs. This study investigated sensorimotor gating characteristics of violent men with diagnoses of both psychosis and dissocial personality disorder (DPD) $(n=21)$ relative to violent men with psychosis alone ( $n=12)$, DPD alone $(n=14)$ and healthy, nonviolent male controls ( $\mathrm{n}=27$ ), using the prepulse inhibition (PPI) paradigm. The results indicated that, relative to the psychosis alone and healthy control groups, the comorbid group had lower PPI, especially at 60-ms prepulse-to-pulse interval. The DPD group took an intermediary position and did not differ from any group. Antisocial personality traits (factor two scores of the psychopathy checklist-revised), and greater severity of childhood psychosocial deprivation (including physical and sexual abuse), were significantly correlated with poor PPI across the clinical sample. The findings suggest diverse sensorimotor gating profiles amongst subgroups of violent offenders, with comorbid psychosis and DPD showing most impairment. This is consistent with a 'double dose' of deficit explanation amongst those with both diagnoses, explained at least in part by presence of antisocial personality traits and childhood psychosocial deprivation.

Key Words: Prepulse Inhibition; Psychosis; Antisocial Personality Disorder; Comorbid; Violence; Offender 


\section{Introduction}

The large majority of those with a mental disorder will never be violent (Walsh and Fahy, 2002) and are more likely to become the victim of violence themselves (Walsh et al., 2003). There is, however, epidemiological evidence to suggest that individuals diagnosed with a psychotic disorder are at a higher risk of engaging in violent behaviour, relative to the general population (e.g. Tiihonen et al., 1997; Eronen et al., 1988; Arseneault et al., 2000; Mullen et al., 2000). This places them at risk of deleterious outcomes, such as incarceration, loss of employment and reduced social contacts, as well as stigma. A greater understanding of violent behaviour in the context of mental disorder should be considered a priority to reduce distress and poor functional outcomes for individuals, and protection as well as education of the wider public.

The aetiology of any violent behaviour is complex and multifaceted (Mullen, 2006). Violence amongst those with psychosis may be no different, with distinct subtypes present and heterogeneous origins (Hodgins, 2008). Some individuals present with antisocial behaviours prior to the onset of psychosis and likely meet criteria for one of the antisocial personality disorders [antisocial personality disorder (ASPD), dissocial personality disorder (DPD) and/or the clinical syndrome of psychopathy (Bo et al., 2011; Volavka and Citrome, 2008)] while others behave violently in the absence of antisocial personality traits (Hodgins, 2008). These two subgroups may have different characteristics, potentially indicating different therapeutic needs. The validity of distinct subgroups (with/without PD) is also strengthened by longitudinal cohort studies, one of which found that individuals with an adult schizophreniform disorder were 2.8 times more likely than those without to have been diagnosed with childhood conduct disorder, equating to around $40 \%$ of the schizophreniform group (Kim-Cohen et al., 2003). This suggests a pervasive pattern of antisocial behavior beginning in childhood and persisting to adulthood. Indeed, in a study of those experiencing their first episode of psychosis, around 34\% of men and $10 \%$ of women had an existing record of criminal conviction, with approximately $20 \%$ and $5 \%$ (respectively) having a record of violent conviction (Hodgins et al., 2011).

Studies focussing on demographic and historical characteristics indicate that individuals with psychosis and an antisocial personality disorder are characterised by pervasive substance abuse, 
attentional problems, poor educational attainment, a lengthy criminal history which precedes illness onset, and commit crimes which are not driven by symptoms (Joyal et al., 2004; Moran and Hodgins, 2004; Steinert et al., 1998). A recent study (Tang et al., 2016) reported poorer executive function, assessed using the Wisconsin Card Sorting Test (WCST) in individuals who had both ASPD and schizophrenia, relative to non-violent individuals with schizophrenia alone. Earlier, Barkataki and colleagues (2005) had reported poor WCST performance in violent individuals with schizophrenia relative to non-violent individuals with schizophrenia alone; although both of their schizophrenia groups were required to be free of ASPD diagnosis, psychopathy scores (antisocial personality traits) were markedly higher in their violent schizophrenia group. A greater understanding of patients with comorbid psychosis and an antisocial personality disorder remains a priority for research since this group makes up a large percentage ( $\sim 5 \%$ ) of individuals utilising forensic mental health services (Blackburn et al., 2003).

Prepulse inhibition (PPI) of the startle response (Graham, 1975), a widely employed psychophysiological model to examine sensorimotor disturbances in a range of neuropsychiatric populations (Braff, 2010; Swerdlow et al., 2014), offers a valuable tool to advance the study of violenceamongst those with comorbid diagnoses of psychosis and an antisocial personality disorder versus psychosis-alone for a number of reasons. Firstly, there is noted convergence between the neural substrates of PPI and the neurobiology of aggression/violence. For example, frontal and temporal lobe deficits have been associated with both reduced PPI (Kumari et al., 2003, 2005a, 2007; Hazlett et al., 1998, 2001; Swerdlow et al., 2008) and the exhibition of violent behaviour (Hoptman, 2003, 2015; Yang and Raine, 2009; Pardini et al., 2014). Secondly, there is evidence from a previous study (Kumari et al., 2005b) for an association between reduced PPI and the severity of violence across groups of patients with schizophrenia and ASPD. Lastly, PPI offers the advantage of not being subject to a number of limitations typically encountered in neuropsychological testing, such as low effort, malingering or symptom exaggeration, with the last two being particularly problematic when assessing forensic groups (Mittenberg et al., 2002).

The primary aim of the present study, therefore, was to examine PPI in violent patients with comorbid psychosis and DPD relative to violent patients with only psychosis or DPD, as well as a 
healthy, non-violent group. DPD is described by the International Classification of Diseases, $10^{\text {th }}$ edition (ICD-10; World Health Organization, 1992), and is aligned to ASPD in the DSM-IV. Although DPD is characterised by more affective/interpersonal difficulties (e.g. callousness, incapacity to maintain relationships) in contrast to the more behaviourally defined ASPD (e.g. violation of rules, impulsivity), there is significant overlap (e.g. irresponsibility, aggression, and failure to conform to social norms). Our secondary aims were to explore the influence of psychosocial deprivation (including physical and sexual abuse) in PPI across groups, given our previous studies showing a higher prevalence of childhood deprivation in offenders with ASPD, followed by schizophrenia, and additional brain deficits in PPIrelevant regions (e.g. the thalamus) in association with a history of childhood deprivation across the groups (Kumari et al., 2013, 2014).

\section{Method}

\subsection{Participants and design}

The study involved four groups: patients with both a psychotic disorder and DPD (“Comorbid”: n=21; 12 with schizophrenia and nine schizoaffective disorder); patients with a psychotic disorder ("Psychosis": n=12; 10 with schizophrenia, one schizoaffective disorder, one delusional disorder), patients with DPD (“DPD”: n=14), and healthy control participants (“Controls”: n=27). Patients were recruited from a high-secure forensic psychiatric hospital in the United Kingdom and all had a history of violence. Male staff from the hospital comprised the control group, who had been assessed using the screening module from the Structured Clinical Interview for DSM Disorders (non-patient version) (First, Spitzer, Gibbon, \& Williams, 2002) and found to be free from mental disorder.

All diagnoses were made by the patient’s responsible clinician (consultant psychiatrist) using the ICD-10 at admission, following a detailed clinical interview. Diagnosis at this hospital is reviewed every six months. Responsible clinicians referred patients who were deemed to have capacity to give consent to participate in research, were clinically stable enough to meaningfully partake, did not pose an imminent risk of violence to researchers, did not have a history of traumatic brain injury, and had normal hearing. All patients were free of current substance abuse (subject to random urine analysis checks as part of their routine clinical care) and non-smokers (as per the hospital policy). As PPI is 
sensitive to smoking (nicotine increases PPI; Hong et al., 2008; Kumari et al., 2001; Postma et al., 2006), any controls who were smokers ( $\mathrm{n}=6$ ) were asked to refrain from smoking for two hours prior to testing. All patients were non-smokers.

The study was reviewed and approved by the National Research and Ethics Service (REC Ref: 14/LO/0238) and West London Mental Health Trust Research and Development (98463/LNW). Participants received $£ 30$ into their hospital accounts (patients) or in cash (controls) upon completion of PPI experiment and additional tasks (not reported here).Demographic, clinical and offence-related variables are displayed in Table 1.

\section{****Table 1 about here ${ }^{* * * *}$}

\subsection{Sample characterisation}

All participants were assessed on estimated premorbid IQ using the Wechsler Test of Adult Reading (WTAR; Wechsler, 2001). In addition, medication was recorded, and the ratings of psychopathy, violence and psychosocial deprivation were obtained for patients as described below.

\section{Antisocial personality traits}

The Psychopathy Checklist - Revised (PCL-R; $2^{\text {nd }}$ Edition) (Hare, 2003) was used as a measure of antisocial personality traits. It is a 20 item checklist, normally scored after interview and comprehensive review of clinical/forensic records. Items are rated as not present (0), partially present (1), or present (2), allowing a maximum score of 40. The PCL-R, as conceptualised by Hare (2003), is composed of two overarching factors relating to a callous, remorseless and arrogant interpersonal style (Factor 1) and a reckless, impulsive, antisocial lifestyle (Factor 2). The PCL-R has shown robust associations with antisocial conduct in meta-analysis (Leistico et al., 2008). It is widely used in clinical forensic settings, and can be applied to individuals with psychosis and PD (e.g. Coid and Ullrich, 2010; Tengström et al., 2000). For the purpose of this study, psychopathy scores were taken from clinical records where available. If psychopathy scores were not available, the PCL-R was rated on the basis of file information only, which has been deemed acceptable for research purposes if the information is detailed enough (Hare, 2003). All participants had a large amount of detailed information contained in their records, often spanning back many years, allowing the adoption of a lifespan perspective when rating. 


\section{Psychosocial deprivation}

Psychosocial deprivation ratings were obtained using the childhood psychosocial deprivation scale following a similar method to Raine et al. (1998). Information was extracted from detailed clinical and forensic records. The following eight subscales were rated on a five point scale using standardised operational criteria ( $0=$ no evidence, $1=$ =minimal, $2=$ partial, $3=$ substantial, $4=$ =xtreme): i) physical abuse, ii) sexual abuse, iii) neglect, iv) foster home placement, v) extreme poverty, vi) criminal parent, vii) severe family conflict viii) a broken home. Thus, a sum of these eight subscales gives an indication of the severity and extent of childhood psychosocial deprivation. Previous investigations (Kumari et al., 2013, 2014) have successfully applied these ratings to patients detained in high-secure forensic hospitals.

\section{Violence}

Violence was rated using the Gunn and Robertson Scale (Gunn and Robertson, 1976). This scale considers a) the frequency of serious violence across the individual's lifetime (previous record), and b) the severity of the most recent violent act (in this study the offence that brought the individual into hospital). A rating for the previous record (0-4) and the index offence (0-4) was made using clinical and forensic records. A score of four for the previous record indicates at least one seriously violent act in which someone's life or health was seriously endangered. A score of four for the index offence reflects lethal or near lethal violence. A total score (0-8) can be generated by summing the two scores. This scale has been used in high-secure forensic psychiatric samples (e.g. Kumari et al., 2005b; Kumari et al., 2013, 2014), and has previously shown good inter-rater reliability for both subscales and the total score ( $r=.82$ to.95; Wong et al., 1993).

\subsection{PPI assessment: paradigm and procedure}

A commercially available human startle response monitoring system (SR-Lab, San Diego, California) was used to generate and deliver the acoustic startle stimuli, and to record and score the electromyographic (EMG) activity for 1000ms starting from the onset of the acoustic startle stimulus. 
The pulse-alone stimulus was a 40-ms presentation of 112- $\mathrm{dB}(\mathrm{A})$ white noise and the prepulse stimulus a 20-ms presentation of 85-dB (A) white noise, both over 70-dB (A) continuous background noise. Acoustic stimuli were presented to participants binaurally through headphones.

The session began with a 2-min acclimatisation period consisting of 70-dB (A) continuous white noise. Participants then received four blocks of 12 trials each, after an initial pulse-alone trial. Each block consisted of three pulse-alone trials, three prepulse trials with a 30-ms prepulse-to-pulse (onset-to-onset) interval, three prepulse trials with a 60-ms prepulse-to-pulse interval and three prepulse trials with a 120-ms prepulse-to-pulse interval, presented in a pseudorandom order with a mean intertrial-interval of $15 \mathrm{~s}$ (range 9-23 s) to attenuate potential habituation effects as much as possible.

Eye-blink component of the startle response was indexed by recording EMG activity of the orbicularis oculi muscle directly beneath the right eye, by positioning two miniature silver/silver chloride electrodes. Recorded EMG activity was band-pass filtered, as recommended by the SR-Lab. A $50-\mathrm{Hz}$ filter was used to eliminate the $50-\mathrm{Hz}$ interference. The EMG data were at first inspected on trial-to-trial basis offline to exclude unusable trials for a particular participant, and then scored blind to diagnoses, using the analytic programme of this system for response amplitude (in arbitrary Analog-toDigit units; 1 unit=2.62 $\mu \mathrm{V})$. Responses $(<5 \%)$ were rejected if there was no visible blink response with the peak occurring within 120-ms of pulse presentation. PPI value was computed for each participant separately for each trial type as (a-b/a) x 100, where "a"=pulse-alone amplitude and "b"=amplitude over prepulse trials. Percent PPI, rather than the absolute amount of PPI (i.e. arithmetic difference between pulse-alone and prepulse trials), was used since this procedure reduces the influence of individual differences in startle responsiveness.

\subsection{General procedure}

Participants were told that the experiment was to measure their attention to a number of brief auditory clicks. No specific instructions were given as to attend or ignore them. Participants were requested to keep their eyes open during the experiment.

\subsection{Data Analysis}


Prior to running any statistical analyses, normality was assessed via reviewing z-scores for skewness and kurtosis with a critical value of \pm 1.96 as recommended by Field (2009). Equality of variance was assessed via Levene's test, with $\mathrm{p}<.05$ indicating significant heterogeneity of variance between groups. Group differences in continuous, normally distributed variables were examined using one way analysis of variance (ANOVA), followed by post-hoc comparisons using Hochberg GT2 tests; these tests are recommended when group sizes differ but variances are equal (Field, 2009). Where variables were nonnormally distributed, logarithmic transformation was attempted; this was successful for 'number of previous offences'. Kruskal-Wallis non-parametric test was used when the assumptions of normality were violated (WTAR, PCL-R total score, childhood psychosocial deprivation), with post-hoc MannWhitney tests where appropriate (Bonferroni correction applied).

The effects of Group on PPI were evaluated with a 4 (Group) x 3 (Trial Type: PPI with 30-ms, 60-ms, 120-ms prepulse-to-pulse interval trials) ANOVA with Trial Type as a within-subjects factor and Group as a between-subjects factor, followed by lower order ANOVAs and the analysis of simple main effects using Hochberg GT2 tests. Effect sizes, where relevant, are reported as partial etasquared (partial $\eta^{2}$ ). Given a significant Group effect in amplitude over pulse-alone trials (see Results), significant group differences in PPI were re-evaluated after co-varying for pulse-alone amplitude.

Correlational analyses (Spearman's Rho) were carried out to examine the relationship between mean PPI (averaged over 30-, 60- and 120-ms prepulse-to-pulse intervals) and the ratings of antisocial personality traits, violence and childhood psychosocial deprivation across all patient groups.

All analyses were performed by SPSS windows (version 22). The $\alpha$ level for significance (twotailed) was set at $\mathrm{p}<.05$ in all analyses unless specified otherwise.

\section{Results}

\subsection{Sample characteristics}

The characteristics of the four study groups (including inferential statistics) are reported in Table 1. They were comparable on age,however, the comorbid group had a significantly lower estimated premorbid IQ than the controls. The control and DPD groups had a significantly higher proportion of white (vs. non-white) participants than the comorbid group, and the control group had a higher 
proportion of white participants than the psychosis group.

The three clinical groups had similarly violent index offences, but the DPD and comorbid groups were characterised by greater violence in their previous offences, as well as a greater number of previous offences, relative to psychosis group. The DPD-alone group had experienced more psychosocial deprivation than the other two clinical groups. The DPD and comorbid groups had higher PCL-R scores than the psychosis group, but did not differ from each other. There was a trend for the comorbid group to have experienced a greater number of years with psychosis, relative to the psychosis group.

\subsection{Startle amplitude and habituation}

There was a significant effect of Group in amplitude over pulse-alone trials $\left(\mathrm{H}_{(3)}=8.72, \mathrm{p}=.033\right)$ indicating significantly lower pulse-alone amplitude, on average, over the entire session in the comorbid group ( $\mathrm{p}=.003$ ) relative to the control group (Table 2). The psychosis, DPD and control groups did not differ significantly from one another (all p>.120). Controls who were smokers did not differ from nonsmokers on pulse-alone amplitude $\left(\mathrm{t}_{(25)}=.671, \mathrm{p}=.51\right)$.

There was significant habituation of the startle response with repeated presentation of pulsealone trials as indicated by a mean percentage decrease ( 12-24\%) in all groups from amplitude over the first to last block of pulse-alone trials (Table 2). The magnitude of habituation did not differ between groups as indicated by a non-significant effect of Group $\left(\mathrm{F}_{(3,70)}=.474, \mathrm{p}=.702\right.$, partial $\left.\eta^{2}=.02\right)$.

\section{****Table 2 about here ${ }^{* * * *}$}

\subsection{PPI}

The overall 4 x 3 (Group $\times$ Trial Type) ANOVA revealed significant main effects of Trial Type $\left(\mathrm{F}_{(2,140)}=13.07, \mathrm{p}<.001\right.$, partial $\left.\eta^{2}=.16\right)$ with a linear trend (linear $\mathrm{F}_{(1,70)}=23.05, \mathrm{p}=<.001$, partial $\eta^{2}=.25$ ) indicating significantly greater PPI on 120-ms, relative to 30-ms, prepulse trials across all groups. There was also a significant main effect of Group $\left(\mathrm{F}_{(3,70)}=4.62, \mathrm{p}=.005\right.$, partial $\left.\eta^{2}=.17\right)$ due to significantly lower PPI in the comorbid group, relative to the control $(\mathrm{p}=.030)$ and psychosis $(\mathrm{p}=.020)$ groups. Other group comparisons were non-significant ( $\mathrm{p}>$.15).Furthermore, there was a significant Group $\mathrm{x}$ Trial 
Type interaction $\left(\mathrm{F}_{(6,140)}=3.11, \mathrm{p}=.007\right.$, partial $\left.\eta^{2}=.12\right)$ which upon further analysis revealed a significant Group effect $\left(\mathrm{F}_{(3,70)}=6.08, \mathrm{p}=.001\right.$, partial $\left.\eta^{2}=.21\right)$ in PPI on 60 -ms (but not on 30-ms or 120-ms) trials showing significantly lower PPI in the comorbid group, relative to the control $(\mathrm{p}=.001)$ and psychosis ( $\mathrm{p}=.010$ ) groups (see Figure 1).The significance of these differences in 60-ms PPI was somewhat reduced $\left(\mathrm{F}_{(3,70)}=2.64, \mathrm{p}=.056\right.$, partial $\eta 2=.102$; comorbid vs controls, $\mathrm{p}=.039$, comorbid vs psychosis, $\mathrm{p}=.09$ ) after covarying for pulse-alone amplitude. Control participants who were smokers did not differ from non-smokers on any PPI indices (all p’s>.64).

****Figure 3 about here****

\subsection{Relationships between the ratings of antisocial personality traits, violence, psychosocial deprivation and PPI}

Across the entire clinical sample (i.e. excluding controls, diagnostic groups collapsed), PCL-R factor 2 scores (behavioural/impulsive/lifestyle factor) were negatively correlated with mean PPI $(\mathrm{p}=.031)$ (Table 3). Psychosocial deprivation scores also correlated negatively with mean PPI ( $\mathrm{p}=.044)$. Ratings of violence (Gunn \& Robertson Scale) and PCL-R Factor 1 scores (affective/interpersonal factor) had non-significant negative correlations with PPI (p’s>.140) (Table 3).

\section{****Table 3 about here ${ }^{* * * *}$}

\section{Discussion}

This study aimed to examine, for the first time, prepulse inhibition (PPI) of the startle response in violent men with comorbid psychosis and dissocial personality disorder (DPD) relative to PPI in violent men with psychosis or DPD alone, as well as healthy, non-violent controls. It further examined the influence of antisocial personality traits, severity of previous violence and psychosocial deprivation. The findings showed reduced PPI, especially with 60-ms prepulse-to-pulse-alone trials, in the comorbid groups relative to the control and psychosis-alone groups. PPI was lower in patients (across all three clinical groups) in association with a high level of behavioural/impulsive/lifestyle factor score and psychosocial deprivation. Finally, the comorbid group also had lower startle amplitude relative to the control group.

Our finding of significantly impaired PPI in the comorbid group (the lowest of all groups), 
especially on 60-ms prepulse-to-pulse intervals trials, suggests that those with both psychosis and DPD may have a 'double dose' of impairment which may not be normalised despite them ( $>80 \%)$ being on stable atypical antipsychotic treatment (Aggernaes et al., 2010; Kumari et al., 1999; Swerdlow et al., 2006; Quednow et al., 2006; Wynn et al., 2007). Although a further explanation for poorer PPI in the comorbid group may be the age of onset for psychosis, which showed a trend to be earlier amongst the comorbid group (Table 1) and has previously been linked to impaired PPI (Kumari et al., 2000). However, a post-hoc exploratory ANCOVA comparing the psychosis and comorbid groups on mean PPI whilst controlling for age of onset of psychosis retained a significant effect of group with a slightly reduced effect size $\left(\mathrm{F}_{(2,30)}=4.52, \mathrm{p}=.019\right.$, partial $\eta^{2}=.204$; without controlling for age of onset $\mathrm{F}_{(1,31)}=9.31, \mathrm{p}=.005$, partial $\left.\eta^{2}=.231\right)$.

The normal range PPI in the psychosis group somewhat replicates the subtler PPI deficit amongst men with schizophrenia in the only other investigation of PPI amongst a violent schizophrenia group, and was previously hypothesised to be due to this group receiving antipsychotic medication (Kumari., 2005b). Atypical antipsychotic medication has been shown to restore PPI to within the normal range in many studies (Aggernaes et al., 2010; Kumari et al., 1999; Quednow et al., 2006; Wynn et al., 2007). However, there was no difference in the proportion of patients prescribed atypical antipsychotics in the comorbid and psychosis groups (see Table 1), thus some other factors which distinguish the groups might be involved.

Antisocial personality traits are a likely candidate. When examining the correlates of mean PPI across the whole sample, we found significant negative correlations with PCL-R factor two. This can be interpreted similarly to that described by Kumari and colleagues (2005b): individuals may become overstimulated at times of high stress and thus fail to restrict themselves, resulting in an array of impulsive and antisocial behaviours, such as violent and non-violent offending, sensation seeking or poor behavioural controls, all encapsulated in factor two scores of the PCL-R.

Previous reports have identified a moderating effect of related personality traits in PPI, for example, in showing an association between high novelty seeking and low PPI in healthy people(Hutchison et al., 1999). The current findings are consistent with previous observations of an association between low PPI and a high level of Psychoticism (Kumari et al., 2008); proposed by 
Eysenck to be characterised by impersonal, emotionally indifferent traits, and lacking empathy and remorse (Eysenck and Eysenck, 1976), and often conceptualised as part of the psychopathy continuum (Heym et al., 2013). Similar personality traits (novelty seeking, disinhibition) have also been observed to moderate PPI sensitivity to drugs in healthy participants (Hutchison et al., 1999; Swerdlow et al., 2009; Talledo et al., 2009), potentially suggesting that the responsiveness to pharmacological compounds amongst individuals with comorbid psychosis and DPD may differ from their non-comorbid counterparts. This is an avenue for future research.

Although a significant relationship between violence severity ratings and PPI was not observed in the current sample, most likely due to a reduced range of scores on the severity of violence (all patients had a history of violence), the strength of the negative correlation between the severity of violence and PPI in this study (rho=-.219) was very similar to that reported previously across the violent ASPD and psychosis groups (rho=-.182) by Kumari and colleagues (2005b). Previous work suggests that the severity of violence and childhood deprivation are related (see Gilbert et al., 2009 for review); indeed these constructs significantly correlate in our sample (rho=.335, $\mathrm{p}=.021)$.

Psychosocial deprivation was significantly negatively correlated with mean PPI. Early developmental stress has been shown to reduce PPI in animal studies (Ellenbroek et al., 1998; Heidbreder et al., 2000; Koenig et al., 2005). There is also some evidence from human studies that corroborates these findings. For example, in a study of neonates (Huggenberger et al., 2013), maternal social stress (high social isolation and less social recognition) was associated with developing significantly less PPI four months after birth, when compared to neonates whose mothers reported less social isolation and more social recognition. The study confirmed that maternal stress was linked to neonatal stress as the maternal awakening cortisol levels were positively correlated with infant mean cortisol level. This indicates that early developmental experiences can exert an effect on PPI functioning, as the typical development of increasing PPI with age (Gebhardt et al., 2012) was not seen amongst infants with early environmental stressors.

In addition, childhood psychosocial deprivation, conceptualised in the same way as in the current study, has been found to be associated with reduced thalamic volume amongst violent individuals with either schizophrenia or ASPD (Kumari et al., 2013), and thalamic dysfunction has been 
linked to PPI disruption in schizophrenia (reviews, Braff, 2010;Takahashi et al., 2011; Swerdlow et al., 2016).Prefrontal cortex and hippocampus aberrations occur in association with childhood trauma and abuse, supposedly due to trauma and abuse related-stress toxicity (review, Riem et al., 2015; Lawson et al., 2017), and also relate to PPI disturbances (reviews, Braff, 2010; Takahashi et al., 2011). Interestingly, childhood maltreatment is found to predict a poor clinical response to antidepressants in depression (Williams et al., 2016), raising the possibility that it may also retard the PPI-normalising effect of antipsychotics due to the emergence of sustained brain deficits in early adulthood.

Lastly, the finding of lower startle amplitude in response to pulse-alone trials across the whole session in the comorbid group, relative to the control group, may be at least partially explained by the presence of antisocial traits. Antisocial personality traits have previously been related to low baseline startle (decreased amplitude; Loomans et al., 2015). Startle amplitude is also observed to be lowered by some antipsychotic drugs including clozapine (Graham et al., 2001). Thus, it may be that a combination of taking antipsychotic medication and being characterised by high levels of antisocial personality traits combined additively to result in a lower startle response amongst the comorbid group.

Some limitations of the study must be acknowledged. The groups were not matched for premorbid IQ and ethnicity, but there is no reason to presume that these parameters unduly affected the findings as all fell within the normal range of intellectual functioning. Further, there is no evidence for an association between PPI and IQ (Swerdlow et al., 2006), and although in one study differences in PPI were observed between African American and European American participants, the results demonstrated that there was greater PPI amongst African Americans (Hasenkamp et al., 2008), and thus the finding of reduced PPI in the comorbid group (who had a higher proportion of non-white participants) is unlikely to be due to ethnic differences. Additionally, the sample was characterised by other comorbidities (Table 1), which was an unavoidable reality when recruiting from a service designed for individuals with highly complex needs. Thus, it cannot be ruled out that some aspects may be attributable to other diagnoses, although this would seem unlikely as there is not a great prevalence of any one comorbidity within groups.

As a related point, diagnoses (psychosis and/or DPD) were not confirmed with an additional structured clinical interview, but were made on the basis of the current clinical diagnosis. However, 
arguably experienced clinicians who are highly involved in each individual patient's care are well placed to formally diagnose, and such diagnoses can thus be considered to have ecological validity. Indeed, patients within high-secure services are consistently monitored by staff, and often have admissions spanning many years, so there is a large amount of information regarding each individual's presentation which may not have been available/obvious from a shorter researcher-administered interview.Finally, the suitability of the healthy control group must be considered. Although all staff working for the health service require a thorough criminal records check before employment (making any significant offending behaviours highly unlikely amongst this group), we did not assess prior antisocial behaviour and/or personality traits amongst staff. Previous research has indicated that forensic hospital staff may be characterised by a 'fearless' disposition, and 'self-centred impulsivity' relative to community controls (Loomans et al., 2015), which given our results indicating an association between antisocial traits and PPI, may be a mediating factor to consider in future investigations.

In conclusion, this investigation suggests diverse sensorimotor gating profiles amongst subgroups of violent offenders, with comorbid psychosis and DPD showing most impairment in this domain. This supports the conceptualisation of a distinct subgroup and is consistent with a 'double dose' of deficit explanation amongst those with both diagnoses. Additionally, this investigation provides evidence to suggest that antisocial personality traits and childhood psychosocial deprivation moderate PPI. 


\section{References}

Aggernaes, B., Glenthoj, B.Y., Ebdrup, B.H., Rasmussen, H., Lublin, H., Oranje, B., 2010. Sensorimotor gating and habituation in antipsychotic-naive, first-episode schizophrenia patients before and after 6 months' treatment with quetiapine. Int. J. Neuropsychopharmacol. 13(10), 1383-1395.

Arseneault, L., Moffitt, T.E., Caps, A., Taylor, P.J., Silva, P.A., 2000. Mental disorders and violence in a total birth cohort. Arch. Gen. Psychiatry 57, 979-986

Barkataki I., Kumari V., Das M., Hill M., Morris R., O'Connell P., Taylor P., Sharma T., 2005. A neuropsychological investigation into violence and mental illness. Schizophr. Res. 74(1),1-13.

Blackburn, R.., Logan, C., Donnelly, J., Renwick, S., 2003. Personality disorders, psychopathy and other mental disorders: co-morbidity among patients at English and Scottish high-security hospitals. J. Foren. Psychiat. Psychol. 14(1), 111-137.

Bo, S., Abu-Akel, A., Kongerslev, M., Haahr, U.H., Simonsen, E., 2011. Risk factors for violence among patients with schizophrenia. Clin. Psychol. Review 31(5), 711-726.

Braff, D.L., 2010 Prepulse inhibition of the startle reflex: a window on the brain in schizophrenia.

Curr. Top. Behav. Neurosci. 4,349-371.

Coid, J., Ullrich, S., 2010. Antisocial personality disorder is on a continuum with psychopathy. Compre. Psychiatry 51(4), 426-433.

Ellenbroek, B.A., Van Den Kroonenberg, P.T.J.M., Cools, A.R., 1998. The effects of an early stressful life event on sensorimotor gating in adult rats. Schizophr. Res. 30(3), 251-260.

Eronen M., Angermeyer M.C., Schulze B., 1998. The psychiatric epidemiology of violent behaviour. Soc. Psychiat. Psychiatric Epidemiol. 33 (S1): 13-23

Eysenck, H.J., Eysenck, S.B.G., 1976. Psychoticism as a dimension of personality. Hodder \& Stoughton, London.

Field, A., 2009. Discovering Statistics using SPSS, 3 ed. SAGE, London.

First, M. B., Spitzer, R. L., Gibbon, M., \& Williams, J. B. W. 2002. Structured Clinical Interview for DSM-IV-TR Axis I Disorders, Research Version, Non-patient Edition. (SCID-I/NP) New York: Biometrics Research, New York State Psychiatric Institute.

Gebhardt, J., Schulz-Juergensen, S., Eggert, P., 2012. Maturation of prepulse inhibition (PPI) in childhood. Psychophysiology 49(4), 484-488.

Gilbert, R., Widom, C.S., Browne, K., Fergusson, D., Webb, E., Janson, S., 2009. Burden and consequences of child maltreatment in high-income countries. The Lancet 373(9657), 68-81.

Graham, F., 1975. The more or less startling effects of weak prestimuli. Psychophysiology 12, 238-248.

Graham, S.J., Langley, R.W., Bradshaw, C.M., Szabadi, E., 2001. Effects of haloperidol and clozapine on prepulse inhibition of the acoustic startle response and the N1/P2 auditory evoked potential in man. 
J. Psychopharmacol. 15(4), 243-250.

Gunn, J., Robertson, G., 1976. Drawing a criminal profile. Br. J. Criminology 16, 156-160.

Hare, R.D., 2003. Manual for the Revised Psychopathy Checklist 2ed. Multi-Health Systems, Toronto, ON, Canada.

Hasenkamp, W., Norrholm, S.D., Green, A., Lewison, B., Boshoven, W., Keyes, M., Duncan, E., 2008. Differences in startle reflex and prepulse inhibition in European-Americans and African-Americans. Psychophysiology 45(5), 876-882.

Hazlett, E.A., Buchsbaum, M.S., Tang C.Y., Fleischman, M.B., Wei, T.C., Byne, W., Haznedar, M., 2001. Thalamic activation during an attention-to-prepulse startle modification paradigm: a functional MRI study. Biol. Psychiatry 50(4): 281-291.

Hazlett, E.A., Buchsbaumm, M.S., Haznedar, M.M., Singer, M.B., Germans, M.K., Schnur, D.B., Jimenez, E.A., Buchsbaum, B.R., Troyer, B.T., 1998. Prefrontal cortex glucose metabolism and startle eyeblink modification abnormalities in unmedicated schizophrenia patients. Psychophysiology 35. 186-198.

Heidbreder, C.A., Weiss, I.C., Domeney, A.M., Pryce, C., Homberg, J., Hedou, G., Feldon, J., Moran, M.C., Nelson, P., 2000. Behavioral, neurochemical and endocrinological characterization of the early social isolation syndrome. Neuroscience 100(4), 749-768.

Heym, N., Ferguson, E., Lawrence, C., 2013. The Psychopathy continuum: Facets of Psychoticism and their associations with psychopathic tendencies. Pers. Indiv. Diff. 54(6), 773-778.

Hodgins, S., 2008. Violent behaviour among people with schizophrenia: a framework for investigations of causes, and effective treatment, and prevention. Philosophical Transactions of the Royal Society of London. Series B, Biological sciences 363(1503), 2505-2518.

Hodgins, S., Calem, M., Shimel, R., Williams, A., Harleston, D., Morgan, C., Dazzan, P., Fearon, P., Morgan, K., Lappin, J., Zanelli, J., Reichenberg, A., Jones, P., 2011. Criminal offending and distinguishing features of offenders among persons experiencing a first episode of psychosis. Early Interv. Psychiatry 5(1), 15-23.

Hong, L.E., Wonodi, I., Lewis, J., Thaker, G.K., 2008. Nicotine effect on prepulse inhibition and prepulse facilitation in schizophrenia patients. Neuropsychopharmacol. 33(9), 2167-2174.

Hoptman, M.J., 2003, Neuroimaging studies of violence and antisocial behavior. J. Psychiatr. Pract. 9(4),265-78.

Hoptman, M.J., 2015. Impulsivity and aggression in schizophrenia: a neural circuitry perspective with implications for treatment. CNS Spectr. 20(3), 280-6. doi: 10.1017/S1092852915000206.

Huggenberger, H.J., Suter, S.E., Blumenthal, T.D., Schachinger, H., 2013. Maternal social stress modulates the development of prepulse inhibition of startle in infants. Dev. Cognit. Neurosci. 84-90.

Hutchison, K.E., Wood, M.D., Swift, R., 1999. Personality factors moderate subjective and psychophysiological responses to d-amphetamine in humans. Exp. Clin. Psychopharmacol. 7(4), 493501.

Joyal, C.C., Putkonen, A., Paavola, P., Tiihonen, J., 2004. Characteristics and circumstances of 
homicidal acts committed by offenders with schizophrenia. Psychol. Med. 34, 433-442.

Kim-Cohen, J., Caspi, A., Moffitt, T.E., Harrington, H., Milne, B.J., Poulton, R., 2003. Prior juvenile diagnoses in adults with mental disorder: Developmental follow-back of a prospective-longitudinal cohort. Arch. Gen. Psychiatry 60(7), 709-717.

Koenig, J.I., Elmer, G.I., Shepard, P.D., Lee, P.R., Mayo, C., Joy, B., Hercher, E., Brady, D.L., 2005. Prenatal exposure to a repeated variable stress paradigm elicits behavioral and neuroendocrinological changes in the adult offspring: Potential relevance to schizophrenia. Behav. Brain Res. 156(2), 251261.

Kumari, V., Antonova, E., Geyer,M.A., Ffytche, D., Williams, S.C., Sharma, T., 2007. A fMRI investigation of startle gating deficits in schizophrenia patients treated with typical or atypical antipsychotics. Int. J. Neuropsychopharmacol. 10(4),463-77.

Kumari, V., Gray, J.A., Soni, W., Geyer, M.A., Mitterschiffthaler, M., Ffytche, D., Vythelingum, G.N., Simmons, A., Williams, S.C.R., Sharma, T., 2003. Neural correlates of prepulse inhibition in normal and schizophrenic subjects: A functional MRI Study. Psychiat. Res: Neuroimag. 122, 99-113

Kumari, V., Premkumar, P., Fannon, D., Aasen. I., Raghuvanshi, S., Anilkumar, A.P., Antonova, E., Peters, E.R., Kuipers, E., 2012. Sensorimotor gating and clinical outcome following cognitive behaviour therapy for psychosis. Schizophr. Res. 134(2-3),232-8. doi: 10.1016/j.schres.2011.11.020.

Kumari, V., Antonova, E., Zachariah, E., Galea, A., Aasen, I., Ettinger, U., Mitterschiffthaler, M.T., Sharma, T., 2005a. Structural brain correlates of prepulse inhibition of the acoustic startle response in healthy humans. NeuroImage 26(4), 1052-1058.

Kumari, V., Antonova, E., Geyer, M.A., 2008. Prepulse inhibition and "psychosis-proneness" in healthy individuals: An fMRI study. Eur. Psychiatry 23(4), 274-280.

Kumari, V., Das, M., Hodgins, S., Zachariah, E., Barkataki, I., Howlett, M., Sharma, T., 2005b. Association between violent behaviour and impaired prepulse inhibition of the startle response in antisocial personality disorder and schizophrenia. Behav. Brain Res. 158(1), 159-166.

Kumari, V., Gudjonsson, G.H., Raghuvanshi, S., Barkataki, I., Taylor, P., Sumich, A., Das, K., Kuipers, E., Ffytche, D.H., Das, M., 2013. Reduced thalamic volume in men with antisocial personality disorder or schizophrenia and a history of serious violence and childhood abuse. Eur. Psychiatry. 28(4), 225234.

Kumari V., Uddin S., Premkumar P., Young S., Gudjonsson G.H., Raghuvanshi S., Barkataki I., Sumich A., Taylor P., Das M., 2014. Lower anterior cingulate volume in seriously violent men with antisocial personality disorder or schizophrenia and a history of childhood abuse. Aust N Z J Psychiatry. 48(2),153-61. doi: 10.1177/0004867413512690.

Kumari, V., Soni, W., Mathew, V.M., Sharma, T., 2000. Prepulse inhibition of the startle response in men with schizophrenia: Effects of age of onset of illness, symptoms, and medication. Arch. Gen. Psychiatry 57(6), 609-614.

Kumari, V., Soni, W., Sharma, T., 1999. Normalization of Information Processing Deficits in Schizophrenia with Clozapine. Am. J. Psychiatry 156(7), 1046-1051.

Kumari, V., Soni, W., Sharma, T., 2001. Influence of cigarette smoking on prepulse inhibition of the acoustic startle response in schizophrenia. Hum. Psychopharmacol.16(4), 321-326. 
Lawson, G.M., Camins, J.S., Wisse, L, Wu, J., Duda, J.T., Cook, P.A., Gee, J.C., Farah, M.J. 2017. Childhood socioeconomic status and childhood maltreatment: Distinct associations with brain structure. PLOS One 12(4):e0175690.

Leistico, A.M.R., Salekin, R.T., DeCoster, J., Rogers, R., 2008. A large-scale meta-analysis relating the hare measures of psychopathy to antisocial conduct. Law \&Human Behavior 32(1), 28-45.

Loomans, M.M., Tulen, J.H.M., Van Marle, H.J.C., 2015. The startle paradigm in a forensic psychiatric setting: Elucidating psychopathy. Crim. Behav. Mental Health 25(1), 42-53.

Mittenberg, W., Patton, C., Canyock, E.M., Condit, D.C., 2002. Base rates of malingering and symptom exaggeration. J. Clinical \& Exp. Neuropsychol. 24(8), 1094-1102.

Moran, P., Hodgins, S., 2004. The correlates of comorbid antisocial personality disorder in schizophrenia. Schiz. Bull. 30(4), 791-802.

Mullen, P.E., Burgess, P., Wallace, C., Palmer. S., Ruschena, D., 2000. Community care and criminal offending in schizophrenia. Lancet, 355(9204), 614-617

Mullen, P.E., 2006. Schizophrenia and violence: from correlations to preventive strategies. Adv. Psychiat. Treatment 12(4), 239-248.

Pardini, D.A., Raine, A., Erickson, K., Loeber, R., 2014. Lower amygdala volume in men is associated with childhood aggression, early psychopathic traits, and future violence. Biol. Psychiatry 75(1).73-80. doi: 10.1016/j.biopsych.2013.04.003.

Postma, P., Gray, J.A., Sharma, T., Geyer, M., Mehrotra, R., Das, M., Zachariah, E., Hines, M., Williams, S.C.R., Kumari, V., 2006. A behavioural and functional neuroimaging investigation into the effects of nicotine on sensorimotor gating in healthy subjects and persons with schizophrenia. Psychopharmacology 184(3-4), 589-599.

Quednow, B.B., Wagner, M., Westheide, J., Beckmann, K., Bliesener, N., Maier, W., Kühn, K.U., 2006. Sensorimotor gating and habituation of the startle response in schizophrenic patients randomly treated with amisulpride or olanzapine. Biol. Psychiatry 59(6), 536-545.

Raine, A., Stoddard, J., Bihrle, S., Buchsbaum, M., 1998. Prefrontal glucose deficits in murderers lacking psychosocial deprivation. Neuropsychiat. Neuropsychol. Behav. Neurol. 11(1), 1-7.

Riem, M.M., Alink, L.R., Out, D., Van Ijzendoorn, M.H., Bakermans-Kranenburg, M.J. 2015. Beating the brain about abuse: Empirical and meta-analytic studies of the association between maltreatment and hippocampal volume across childhood and adolescence. Dev. Psychopathol. 27(2):507-520.

Steinert, T., Voellner, A., Faust, V., 1998. Violence and Schizophrenia: Two Types of Criminal Offenders. Eur. J. Psychiatry 12(3), 153-166.

Swerdlow, N.R., Braff, D.L., Geyer, M.A. 2016. Sensorimotor gating of the startle reflex: what we said 25 years ago, what has happened since then, and what comes next. J. Psychopharmacol. 30(11):10721081.

Swerdlow, N.R., Light, G.A., Cadenhead, K.S., Sprock, J., Hsieh, M.H., Braff, D.L., 2006. Startle gating deficits in a large cohort of patients with schizophrenia: Relationship to medications, symptoms, neurocognition, and level of function. Arch. Gen. Psychiatry 63(12), 1325-1335. 
Swerdlow N.R., Light, G.A., Sprock, J., Calkins, M.E., Green, M.F., Greenwood, T.A., ... \& Radant, A.D., 2014. Deficient prepulse inhibition in schizophrenia detected by the multi-site COGS. Schizophr. Res. 152(2), 503-512.

Swerdlow N.R., Weber M., Qu Y., Light G.A., Braff D.L., 2008. Realistic expectations of prepulse inhibition in translational models for schizophrenia research. Psychopharmacology 199(3),331-88. doi: 10.1007/s00213-008-1072-4

Swerdlow, N.R., Van Bergeijk, D.P., Bergsma, F., Weber, E., Talledo, J., 2009. The effects of memantine on prepulse inhibition. Neuropsychopharmacology 34(7), 1854-1864.

Takahashi, H., Hashimoto, R., Iwase, M., Ishii, R., Kamio, Y., Takeda, M. 2011. Prepulse inhibition of startle response: recent advances in human studies of psychiatric disease. Clin. Psychopharmacol. Neurosci. 9(3):102-110.

Talledo, J.A,, Sutherland, Owens, A.N., Schortinghuis, T., Swerdlow, N.R. 2009. Amphetamine effects on startle gating in normal women and female rats. Psychopharmacology 204(1):165-175.

Tang, D.Y., Liu, A.C., Lui, S.S., Lam, B.Y., Siu, B.W., Lee, T.M., Cheung, E.F., 2016. Facial emotion perception impairments in schizophrenia patients with comorbid antisocial personality disorder. Psychiat. Res. 236, 22-27.

Tengström, A., Grann, M., Långström, N., Kullgren, G., 2000. Psychopathy (PCL-R) as a predictor of violent recidivism among criminal offenders with schizophrenia. Law \& Human Behavior 24(1), 4558.

Tiihonen J., Isohanni M., Rasanen P., Koiranen M., 1997. Specific major mental disorders and criminality: a 26-year prospective study of the 1966 northern Finland birth cohort. Am. J. Psychiatry; $154,840-845$

Volavka, J., Citrome, L., 2008. Heterogeneity of violence in schizophrenia and implications for longterm treatment. Int. J. Clin. Practice 62(8), 1237-1245.

Walsh, E., Fahy, T., 2002. Violence in society : Contribution of mental illness is low. B.M.J. 325(7363), 507-508.

Walsh, E., Moran, P., Scott, C., McKenzie, K., Burns, T., Creed, F., Tyrer, P., Murray, R.M., Fahy, T., 2003. Prevalence of violent victimisation in severe mental illness. Br. J. Psychiatry 183, 233-238.

Wechsler, D., 2001. Wechsler Test of Adult Reading. San Antonio, TX: Psychological Corporation

Wong, M., Lumsden, J., Fenton, G., Fenwick, P., 1993. Violence ratings of special hospital patients. J. Forensic Psychiatry 4(3), 471-480.

World Health Organization, 1992. The ICD-10 classification of mental and behavioural disorders: clinical descriptions and diagnostic guidelines. World Health Organization, Geneva.

Williams, L.M., Debattista, C., Duchemin, A.M., Schatzberg, A.F., Nemeroff, C.B. 2016. Childhood trauma predicts antidepressant response in adults with major depression: data from the randomized international study to predict optimized treatment for depression. Transl. Psychiatry 3;6:e799.

Wynn, J.K., Green, M.F., Sprock, J., Light, G.A., Widmark, C., Reist, C., Erhart, S., Marder, S.R., Mintz, J., Braff, D.L., 2007. Effects of olanzapine, risperidone and haloperidol on prepulse inhibition 
in schizophrenia patients: A double-blind, randomized controlled trial. Schizophr. Res. 95(1-3), 134142.

Yang, Y., Raine A., 2009. Prefrontal structural and functional brain imaging findings in antisocial, violent, and psychopathic individuals: a meta-analysis. Psychiatry Res. 174(2),81-8. doi:

10.1016/j.pscychresns.2009.03.012 
Table 1 - Demographic, clinical and offence related variables for the four groups, with inferential statistics

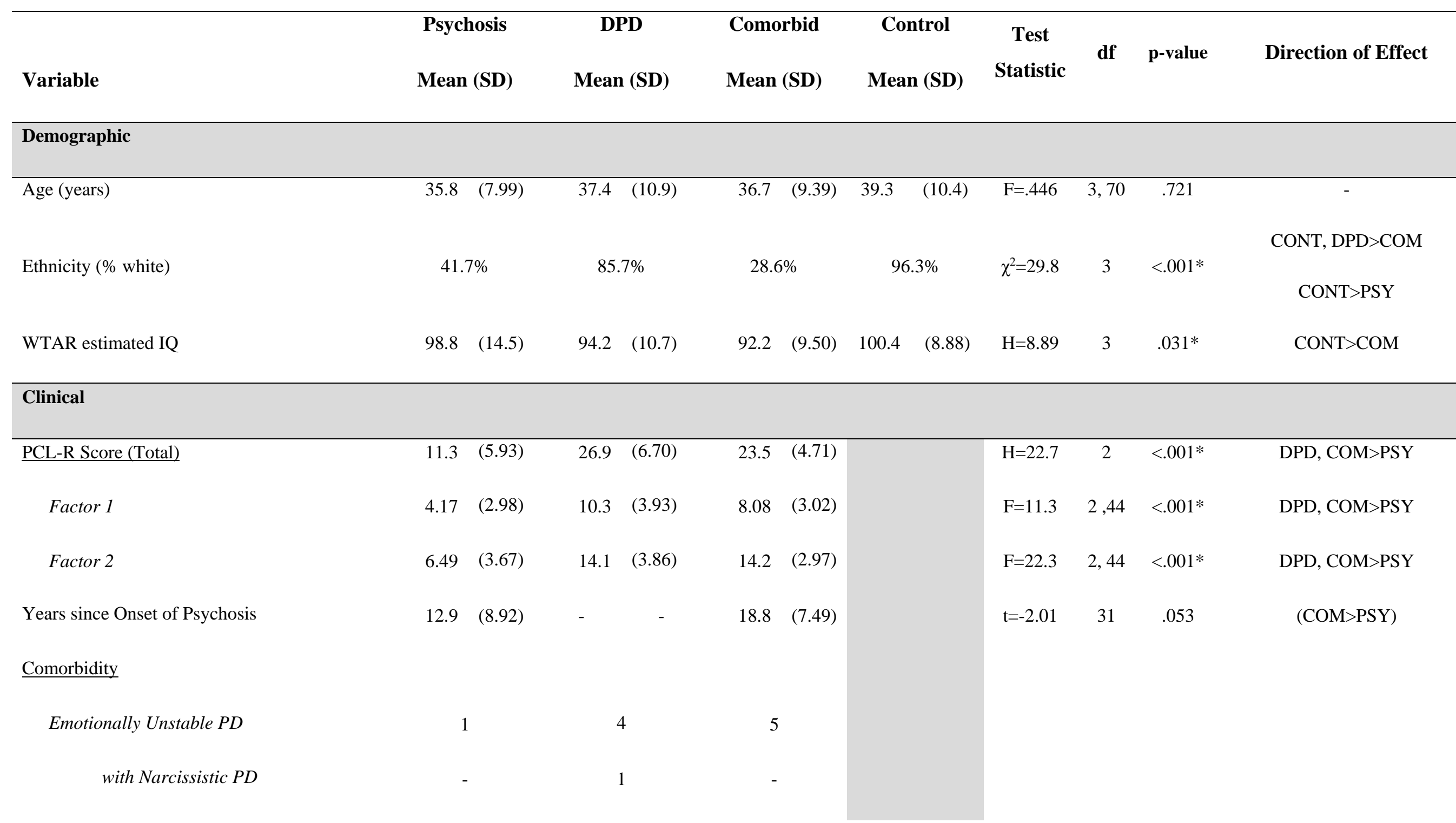


with Paranoid PD

Paranoid PD

Narcissistic PD

Autism Spectrum Disorder

Generalised Anxiety Disorder

Hyperkinetic Disorder

Medication Type (\%)

Typical Antipsychotic

Atypical Antipsychotic

Mood Stabiliser

Antidepressant

Benzodiazepine

Psychosocial

Childhood Psychosocial Deprivation Total

$7.42 \quad(6.16)$
0

0

0

$28.6 \%$

$\chi^{2}=2.44 \quad 2 \quad .296$

$\chi^{2}=5.97 \quad 2 \quad .051$

(COM, PSY >DPD)

$\chi^{2}=3.73 \quad 2 \quad .155$

$\chi^{2}=1.65 \quad 2 \quad .437$

$\chi^{2}=6.04 \quad 2 \quad .049 * \quad$ DPD $>$ PSY, COM
$81.0 \%$

$38.1 \%$

$14.3 \%$

$14.3 \%$
$0 \%$

$35.7 \%$

Offence Related 
Gunn and Robertson: Index Offence

Gunn and Robertson: Previous Record

Number of Previous Offences
$3.42 \quad(.792)$

$1.50 \quad(1.24)$

$3.67 \quad(4.58)$
$3.14 \quad(.949)$

$20.1 \quad$ (18.3)
$3.19 \quad(.814)$

$2.71 \quad(1.15)$

$15.6 \quad(14.0)$
$\mathrm{F}=.370$

$F=7.48$

$F=13.0$
2,44

$2,44 \quad .002 *$

$2,44<.001 *$
DPD, COM $>$ PSY

DPD, COM $>$ PSY 
Table 2 - Mean (standard error of the mean, SEM) response amplitudes over the four blocks of three pulse-alone trials each in the four study groups.

Mean (SEM) of Startle Amplitude (analogue-to-digital units)

\section{$\begin{array}{llll}\text { Psychosis } & \text { DPD } & \text { Comorbid } & \text { Controls }\end{array}$}

\begin{tabular}{lcccc}
\hline Block 1 & $498.17(74.22)$ & $350.40(68.71)$ & $300.16(56.10)$ & $482.69(49.48)$ \\
Block 2 & $350.19(56.54)$ & $291.19(52.34)$ & $220.94(42.74)$ & $425.30(37.69)$ \\
Block 3 & $360.72(52.51)$ & $239.98(48.61)$ & $214.07(36.69)$ & $378.94(35.00)$ \\
Block 4 & $368.08(55.09)$ & $227.43(51.00)$ & $214.94(41.64)$ & $379.32(36.73)$ \\
Overall & $394.29(55.05)$ & $277.25(50.96)$ & $237.53(41.61)$ & $416.56(36.68)$ \\
Mean \% Change* & $-15.69 \%$ & $-24.49 \%$ & $-22.88 \%$ & $-17.17 \%$
\end{tabular}

*Block 1 to Block 4; \% change calculated for each subject and a mean of these values per group is reported, thus controls for inter-individual variation in startle amplitude. Raw (uncorrected) amplitudes are reported across blocks. 
Table 3 - Correlations between the ratings of antisocial personality traits, violence and psychosocial deprivation and mean PPI.

\section{Mean PPI}

\begin{tabular}{lcc}
\hline All Patients & rho & $\mathrm{p}$ \\
\hline PCL- R- Factor 1 - affective/interpersonal & -.118 & .428 \\
PCL- R- Factor 2 - behavioural/lifestyle & -.316 & $.031^{*}$ \\
Childhood Psychosocial Deprivation & -.295 & $.044^{*}$ \\
Gunn \& Robertson - Violence Severity Total & -.219 & .140 \\
\hline
\end{tabular}

${ }^{*} \mathrm{p}<.05 ;$ PCL-R - Psychopathy Checklist - Revised 
Figure 1 - PPI with 30-ms, 60-ms and 120-ms prepulse-to-pulse intervals, classified by Group. Error bars are \pm 1 SEM.

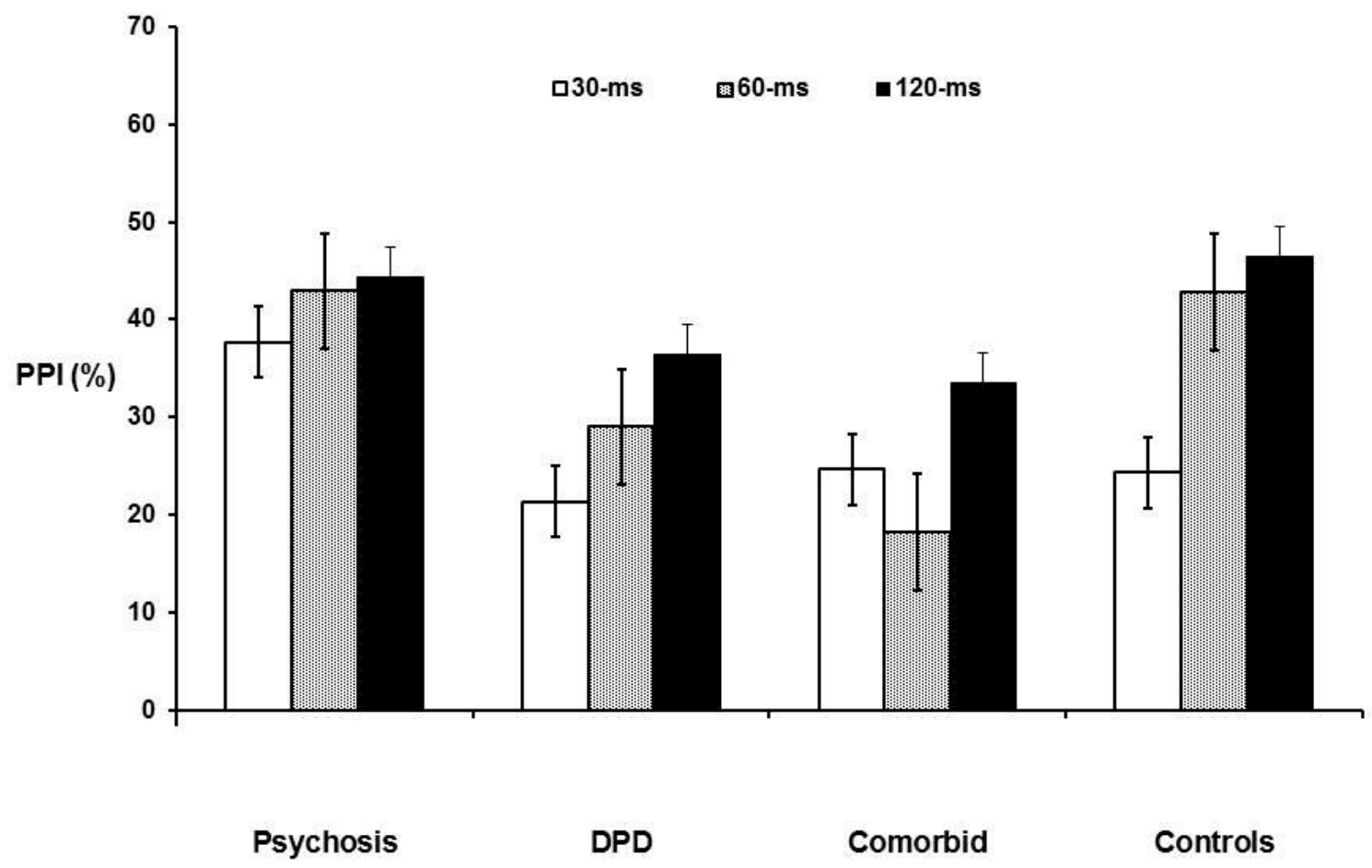

